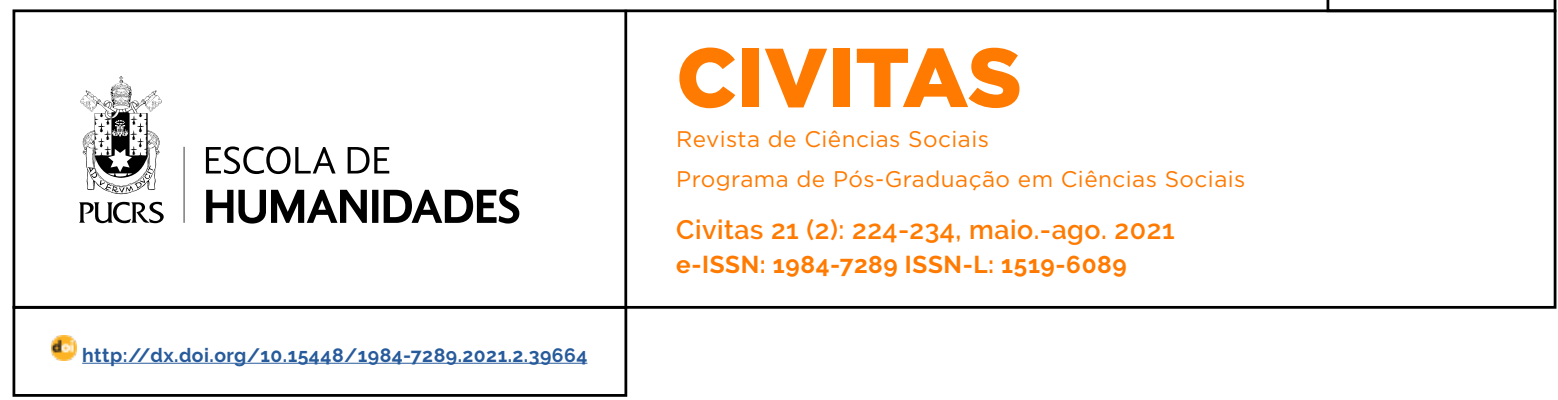

DOSSIÊ: DIGITALIZAÇÃO E DATAFICAÇÃO DA VIDA: PERVASIVIDADE, UBIQUIDADE E HIBRIDISMOS CONTEMPORÂNEOS

\title{
Máquinas de previsão e controle e a crise do possível
}

\author{
Machines of prediction and control and the crisis of the possible \\ Máquinas de predicción y control y la crisis de lo posible
}

\section{Alana Soares \\ Albuquerque $^{1}$}

orcid.org/0000-0002-8455-9180

alana_albuquerque@hotmail.com

Recebido em: 30 nov 2020.

Aprovado em: 1 abr. 2021

Publicado em: 24 ago. 2021

\section{(c) (i)}

Artigo está licenciado sob forma de uma licença Creative Commons Atribuição 4.0 Internacional.
Resumo: O presente trabalho, fruto de uma discussão realizada em uma tese de doutorado, analisa como que o possivel, categoria temporal pertencente ao futuro, vem sendo cada vez mais capturado por mecanismos de poder específicos da chamada sociedade de controle. O campo dos possiveis vem sendo circunscrito hoje em dia não só por visões homogeneizantes de futuro que predominam no imaginário (como o futuro tecnológico da ficção científica), como também por mecanismos de controle cada vez mais refinados que preveem e induzem nosso próximo passo, empobrecendo nossa capacidade de escolha, nossa imaginação e nossas subjetividades. Esse ensaio analisa essas diferentes formas de sequestro dos possiveis, passando pelo maquinário das ciências modernas e pela especulação financeira, até chegar nas informações hoje armazenadas no big data, esse fluxo de dados alimentado pelos algoritmos que controlam e preveem nossas próximas escolhas. O trabalho questiona, ao final, que outros tipos de especulação poderiam, ao contrário de fechar o campo de possiveis, expandi-lo e intensificá-lo, mantendo-se abertos à diferença, à incerteza e às contingências.

Palavras-chave: Possivel. Sociedade de controle. Big Data. Especulação. Futuro.

Abstract: This work, the result of a discussion carried out in a PhD thesis, analyzes how the possible, a temporal category that belongs to the future, has been increasingly captured by mechanisms of power characteristic of the so-called societies of control. The field of possibilities is being circumscribed today not only by homogenizing visions of the future that predominate in the imaginary (such as the technological future of science fiction), but also by increasingly refined mechanisms of control that predict and induce our next steps, diminishing our ability to choose, our imagination and our subjectivities. This essay analyzes these different forms of hijacking the possible, going through the machinery of modern sciences and financial speculation, until getting to the information currently stored as big data, the data flow fed by the algorithms that control and predict our next choices. The paper questions, at the end, what other types of speculation could, instead of closing the field of possibilities, expand and intensify it, remaining open to difference, uncertainty and contingencies. Keywords: Possible. Society of control. Big Data. Speculation. Future.

Resumen: El presente trabajo, resultado de una discusión realizada en una tesis doctoral, analiza como lo posible, categoría temporal perteneciente al futuro, ha sido capturado cada vez más por mecanismos de poder propios de la llamada sociedad de control. Hoy en día el campo de posibilidades se está circunscribiendo no solo por visiones homogeneizadoras de futuro que predominan en el imaginario (como el futuro tecnológico de la ciencia ficción), sino también por mecanismos de control cada vez más refinados que predicen e inducen nuestro próximo paso, empobreciendo nuestra capacidad de elegir, nuestra imaginación y nuestras subjetividades. Este ensayo analiza estas diferentes formas de secuestrar lo posible, pasando por la maquinaria de las ciencias modernas y la especulación financiera, hasta llegar a la información actualmente almacenada en el big data, ese flujo de datos alimentado por los algoritmos que controlan y predicen nuestras próximas elecciones. El trabajo cuestiona, al final, que otros tipos de especulación podrian, en lugar de cerrar el campo de posibilidades, 
expandirlo e intensificarlo, permaneciendo abiertos a la diferencia, la incertidumbre y las contingencias.

Palabras clave: Posible. Sociedad de control. Big data. Especulación. Futuro.

\section{O possivel como futuridade}

Gostariamos de iniciar essa discussão explorando filosoficamente o conceito de possivel, para depois nos debruçarmos sobre o que estamos nos referindo aqui como sua crise, ocasionada não só por um fechamento do futuro no campo do imaginário, dada a predominância do futuro capitalista em nosso horizonte de expectativas - aquilo que Mark Fisher (2009) chamou de realismo capitalista -, como também por diversos mecanismos de predição e controle que sequestram o possivel transformando-o em provável ou necessário, fenômeno esse no qual pretendemos nos focar ao longo deste ensaio.

Podemos começar afirmando que, do ponto de vista de sua temporalidade, os possiveis pertencem à categoria do futuro, e o futuro é, por excelência, o tempo do possivel, daquilo que ainda não se realizou, mas que está contido no presente por meio de futuridades, ou seja, elementos de futuro que se instalam no agora, e que, como uma espécie de isca, nos atraem para um determinado horizonte. ${ }^{2}$ Mas o que significa dizer que algo é possivel? Qual é o modo de existência dos possiveis e como eles agem no presente? Para o filósofo e sociólogo Gabriel Tarde (2007), o possivel corresponde a nossa capacidade de dizer "se...", ou seja, é o não existente concebido. Na filosofia de Tarde, a realidade contém um campo de virtualidades que carrega todo um conjunto de possiveis que podem ou não ser realizados. O virtual existe dessa maneira como um reservatório de potências não efetuadas, como uma força latente e expectante que insiste ou "faz pressão" sobre o presente. E por que esse excesso de possivel sobre o real precisa existir? Qual a função dos possíveis, considerando que a maioria deles nunca irá se realizar?
Para Tarde (2007), os possíveis não realizáveis existem porque há sempre um excesso de potência sobre o ato. A ação nunca é toda vontade, e o efeito da força nunca é toda a força. Nós não podemos conceber a realidade sem as virtualidades, ou sem esse excesso de potência, e por isso a realização de todas as possibilidades implicaria em uma contradição. Há uma infinidade no campo dos possíveis, mas precisa haver uma finitude no mundo. Disso resulta a necessidade dos impedimentos de nascer. $\mathrm{O}$ desenvolvimento de cada ser só é obtido ao preço do aborto de alguma coisa da qual ele toma o lugar. Não fazemos um movimento, seja corporal, seja mental, sem, com isso, aniquilar mundos possiveis, germes, seres vivos, ideias etc. Os possiveis não realizados são necessários porque eles agem como os espaços vazios em relação aos corpos, ou seja, são indispensáveis ao movimento. Mesmo que a realização de todos os possiveis seja uma contradição, porque isso esgotaria a dimensão virtual da realidade, o autor nos lembra que convém reconhecer na imaginação uma tendência à realização de todas as possibilidades de combinações mentais. A tendência à realização de todos os possiveis parece "ser o sonho impotente e a sede insaciável do Universo" (Tarde 2007, 231). As leis e as forças particulares de que derivam, ao excluírem uma infinidade de possibilidades (ao mesmo tempo que permitem pensar e afirmar as possibilidades subsistentes) parecem ser a direção e o freio desse profundo desejo (Tarde 2007).

Os possiveis, fazendo parte da dimensão virtual da realidade - ou seja, de tudo aquilo que ainda não foi atualizado -, estão, portanto, inscritos no momento presente (Tarde 2007; Debaise e Stengers 2017; Shaviro 2018; Berardi 2017). O possível está latente na realidade e precisa ser efetuado, mas ele não realiza esse processo sozinho. É aí que entra nossa potência de agir. Enquanto as possibilidades são um conteúdo inscrito na

\footnotetext{
2 O termo futurity aparece com frequência na obra de autores como Elizabeth Grosz (2004), Brian Massumi (2010), Steven Shaviro (2018) dentre outros escritores de língua inglesa, com o sentido que estamos trazendo aqui. Consideramos importante realizar tal definição, pois na lingua portuguesa o termo não costuma aparecer em textos filosóficos, nem com a profundidade e importância que esses autores the conferem ao diferenciá-lo da palavra futuro, que possuiria, por si, uma dimensão mais totalizante. Preferimos falar em futuridades, em vez de futuro, justamente para ressaltar tal caráter de multiplicidade e possibilidade que o termo carrega.
} 
presente composição do mundo, a potência é a energia subjetiva que instaura as possibilidades e as atualiza, ela é a condição para a passagem do possivel à realidade. A potência é o que permite a mudança da dimensão zero de informação para a multidimensionalidade do corpo e do acontecimento. Para passar de virtualidade à atualidade, a possibilidade precisa estar corporificada (embodied) em um sujeito e, para isso, esse sujeito precisa de potência. A potência é, portanto, a condição que permite a transformação (Berardi 2017). Para virem à existência, os possiveis precisam ser notados (receber importância) e efetuados, no sentido em que Lapoujade (2017) afirma que os modos de existência precisam de gestos instauradores. Quando imaginamos um determinado futuro, tornamo-nos corpo de passagem para as possibilidades.

Nossa potência de criar e efetuar possiveis é, por sua vez, sempre delimitada por relações de poder que incidem sobre ela. Berardi (2017), em termos foucaultianos, define o poder como uma espécie de grade de seleção que incide sobre a estrutura do presente no formato de uma prescrição. O poder faz a seleção e a execução de algumas possibilidades, enquanto simultaneamente exclui outras. Em resumo, ele se expressa por um regime de visibilidade e invisibilidade, que enfatiza e implementa um plano no qual as possibilidades se desenvolvem. O poder, portanto, reduz o campo de possibilidades a uma ordem prescritiva, sujeitando o conteúdo do possivel a um determinado código gerador. Recorrendo a Spinoza, Berardi (2017) afirma que o poder é aquilo que nos afeta no sentido de diminuir nossa potência de agir no mundo. A gama de possibilidades é, enfim, constantemente aberta pela potência criativa das subjetividades e limitada pelas relações de poder, e é justamente uma relação permanente entre esses três termos o que move a produção da realidade: possibilidade (conteúdo), potência (energia) e poder (forma).

Nesse ponto, é importante lembrar que essa grade de poder que seleciona os possiveis incide não apenas em sua efetuação, ou seja, em sua realização no mundo, mas também em sua própria criação. Os possiveis não existem a priori, apenas esperando para virem à realidade, mas precisam ser criados, para só depois, então, poder se realizar. Para que os possiveis existam, certas condições devem já ter sido colocadas, pois o possivel só pode existir naquilo que o expressa, nas condições que o fizeram emergir. Deleuze e Guattari (2010) usam o seguinte exemplo quando se referem ao modo de existência do possivel: em um mundo calmo e repousante surge um rosto assustado que olha alguma coisa fora de nosso campo de visão. Esse mundo possivel (a possibilidade de um mundo assustador) não é real - ou não o é ainda -, mas ainda assim não deixa de existir, pois se expressa no rosto assustado. Se os possiveis precisam ser criados, o que é, enfim, que os possibilita?

Assim como o aparecimento de um novo corpo faz crescer o espaço, o aparecimento de um novo fato aumenta as possibilidades do mundo (Tarde 2007). Podemos dizer que é o acontecimento, portanto, aquilo que abre um novo campo de possiveis (Lazzarato 2006). Um acontecimento, ao se atualizar, nunca o faz por completo, restando sempre uma carga de virtualidades ligadas à sua emergência, que, por sua vez, insistem no presente, fazendo com que o acontecimento ecoe e não se reduza ao instante em que ocorreu. Lazzarato (2006) utiliza o exemplo dos movimentos políticos para pensar nessa instauração de mundos possiveis pelo acontecimento. $O$ autor critica a política como a realização de um projeto, o que estaria presente, por exemplo, no movimento comunista. Nesse tipo de projeto, possui-se o futuro como imagem, e o realizável é elevado apenas ao grau do necessário. No contexto atual, não basta que os movimentos anticapitalistas apenas repitam o slogan de que "um outro mundo é possivel", mas condições para sua efetuação precisam ser instaladas no agora. É nesse sentido que Lazzarato e outros autores como Benjamin (2012), Deleuze e Guattari (2010), Lapoujade (2016) etc. criticam as utopias de espera e os projetos políticos a longo prazo, valorizando, por outro lado, a revolução enquanto acontecimento que transforma o presente.

A invenção de mundos possiveis precisa, portanto, da potência do acontecimento que 
irrompe no presente, e da potência de nossa imaginação que deve enfrentar os constrangimentos impostos por toda sorte de prescrições que circunscrevem o campo das possibilidades. Pensando no sentimento de "crise do futuro" que autores como Berardi (2011) indicam, instalado principalmente pelo sentimento de morte dos sonhos utópicos, pelo chamado "fim da história" ou pela ideia de que certo fim do mundo está próximo, discurso esse que, devemos lembrar, extrapola hoje o campo da ficção em direção ao campo das ciências (Danowski e Viveiros de Castro 2014), poderíamos dizer que ele corresponde, nos termos que estamos colocando aqui, a uma crise no campo dos possiveis. A perspectiva de um futuro catastrófico - seja a que prolifera hoje nas distopias da ficção científica, seja a afirmada por ciências empíricas como a climatologia, a geofísica, a bioquímica etc. -, ou, ainda, da falta de futuro propriamente dita, significa um certo esgotamento não só no campo da realização dos mundos possiveis, como em sua própria criação enquanto possiveis, entendendo que os possiveis precisam ser criados a partir de um acontecimento que produza diferença.

\section{Crise e esgotamento dos possiveis}

Quando predomina, por exemplo, no campo da ficção científica clássica, a imaginação de futuros que não passam de uma extrapolação do presente, ou, podemos dizer, do próprio capitalismo, já que se dão por uma intensificação de certas tendências que se sobressaem sobre outras (ou seja, pela seleção de um possível), o campo de possibilidades se vê cada vez mais capturado por mecanismos de poder, ou por um certo regime de visibilidade (Foucault cf. Berardi 2017) que incide sobre as escolhas. É como se de certa forma aceitássemos, resignados, que estamos presos aos atuais modos de vida capitalistas, fixados em um presente em expansão, cujo futuro corresponde apenas a mais do mesmo. Todo futuro possivel é o futuro do próprio capitalismo (Fisher 2009). Aqui predomina uma temporalidade (aceleracionista) e uma determinada cronopolítica (Eshun 2003; Kaiser 2015), uma política que incide sobre o tempo e que governa o futuro. Como ampliar o campo de possibilidades, ou instaurar possiveis, considerando que esses vêm sendo cada vez mais restringidos por visões homogeneizantes do futuro, que colocam em nosso horizonte o futuro tecnológico como o único possivel, seja em sua visão utópica e salvacionista, seja em sua visão distópica e escatológica?3

Recorrendo aos personagens de Beckett, Deleuze (2010) usa as expressões cansaço e esgotamento para se referir a dois processos diferentes de exaustão dos possiveis: enquanto o cansaço se refere a uma incapacidade de realizar as possibilidades, de fazer uma escolha entre outras, o esgotamento, um estado mais profundo do que o cansaço, corresponde a uma incapacidade de criar possibilidades. Nesse último processo, é o próprio possivel que se esgota. Se o cansado não pode mais realizar, "o esgotado não pode mais possibilitar" (Deleuze 2010, 67). Enquanto a realização dos possiveis procede por exclusão, pois ela supõe preferências e objetivos que variam sendo essas variações, ou disjunções exclusivas (ou/ou) o que acaba cansando -, o esgotamento dos possiveis procede pela combinação, ou por disjunções inclusivas (e/e). O esgotado renuncia toda necessidade, preferência, finalidade, significação... ele é forçado a substituir seus projetos por tabelas e programas sem sentido.

Se formar séries exaustivas de coisas é uma maneira de esgotar o possivel, compreendemos que esse esgotamento se dá, portanto, não por uma falta de possiveis, mas em função de uma espécie de saturação do espaço-tempo necessário para a criação de novos possiveis. É esse espaço do novo que está saturado pelas

\footnotetext{
3 É importante ressaltar que, quando falamos nessa visão homogeneizante do futuro, estamos nos referindo a um tipo de futuro que foi por muito tempo imaginado pelo que estamos chamando aqui de ficção científica clássica, aquela que surge na literatura do final do século 19, embalada pela empolgação em torno das máquinas decorrente principalmente da Revolução Industrial, e que vai predominar nos filmes hollywoodianos até hoje, ou seja, o futuro como extrapolação tecnológica e aceleração ou esgotamento do capitalismo. Apesar disso, reconhecemos que existem, sim, movimentos na ficção científica que mais recentemente se esforçam para imaginar outros futuros que não o do desenvolvimento tecnológico, como o movimento feminista, por exemplo.
} 
previsões, prescrições, probabilidades, pela serialidade que produz apenas o mesmo. Talvez possamos relacionar a ciência da combinatória e a formação de séries exaustivas ao próprio movimento de acumulação do capitalismo, que hoje se volta não apenas à acumulação de bens e de capital, mas de informações. Nas palavras de Pelbart (1993), o futuro está estocado na memória do computador. Devemos lembrar que o anseio da informática hoje é a informação total, o big data, uma memória absoluta que pode não só prever os acontecimentos, mas reagir a eles antecipando-se ao seu advento, neutralizando-os. É como se o futuro já estivesse presente, e por isso impossibilitado a se apresentar como desconhecido, ou como abertura ao devir. Podemos reconhecer nesse anseio da informática um desejo que está já no âmago das próprias ciências desde seu surgimento: prever, calcular, antecipar... é, enfim, o excesso de informações sobre o futuro, e não a sua falta, o que nos imobiliza e diminui nossa potência de criar possiveis.

Berardi (2017) interpreta essa crise na imaginação de futuros como um efeito da impotência de nossa subjetividade frente a mecanismos de poder cada vez mais complexos, que, no estado atual da sociedade de controle (Deleuze 1992), aperfeiçoam-se no sentido de uma maior eficiência em sua capacidade de previsão e de antecipação de comportamentos, uma particular forma de captura do futuro. A impotência das subjetividades é resultante do controle total por parte de um tipo de poder que atua hoje independentemente da vontade humana, pois está inscrito na textura automatizada da técnica e da linguagem. São os algoritmos que preveem nosso próximo click, nossa próxima compra, que moldam nossos gostos, que sabem de antemão as palavras que vamos digitar... O poder preditivo da máquina global contemporânea reside, hoje, na habilidade de ler diariamente grandes fluxos de dados (big data) para com isso moldar nossos comportamentos futuros (Berardi 2017).

O que o big data possibilita hoje é uma espécie de "protocolamento total da vida", pois aspira-se em todo lugar a uma exploração máxima da in- formação. A chamada "internet das coisas", por exemplo, permite cada vez mais que os objetos que nos cercam nos observem, registrem informações sobre nós, criem bancos de dados com nossos padrões de comportamento, a partir do qual torna-se possivel prevê-los. Todas essas máquinas e coisas que nos cercam e que produzem e compartilham sem cessar informações sobre o que fazemos (ou sobre o que deixamos de fazer) participam ativamente desse processo de protocolamento (Han 2018).

Se os discursos atuais sobre o fim do mundo, por exemplo, representam uma forma especifica de esgotar o campo do possivel, posto que instalam a "falta de futuro" no horizonte de nossas expectativas, aqui nos deparamos com um outro tipo de esgotamento dos possiveis. Enquanto esses discursos fazem parte de uma dimensão mais macropolítica (Deleuze e Guattari 2012) da produção de futuros, pois se baseiam em relatórios cientificos para realizar uma previsão generalizante e a longo prazo, o tipo de previsão realizada pelas tecnologias da informação faz parte de uma dimensão mais micropolitica, que captura o futuro de uma forma mais individual e personalizada. Esse tipo de previsão age em um nível molecular e de curto prazo, calculando e determinando nossos passos seguintes, o que faz dela uma das principais maneiras pela qual o possivel se vê, hoje, cada vez mais transformado em provável.

\section{Máquinas de previsão e controle}

Dizer que o futuro está estocado na memória do computador significa que ele pode ser submetido a previsões cada vez mais exatas. A quantidade de dados acumulados em uma escala vertiginosa permite prever as condutas, os focos de epidemias, as zonas de conflito, os comportamentos de risco etc. Essa forma de dispor do futuro pode soar para alguns como uma utopia na qual nos vemos como verdadeiros senhores do tempo, pois exercemos sobre o futuro uma forma de controle nunca vista antes. Podemos prevê-lo e determiná-lo através de estatísticas cada vez mais precisas, alcançando, assim, um almejado estado de risco zero, um estado que 
nos protege das surpresas, das rupturas, dos acontecimentos, neutralizando-os antes que aconteçam. O tempo do espaço informacional, ou dos grandes fluxos de dados, é o tempo da predição, e quanto mais esse espaço informacional se expande, dominando, por assim dizer, o próprio tempo (o tempo do futuro), mais a dimensão dos possiveis se retrai (Lapoujade 2016).

Citando como exemplo um provável futuro descrito por Bill Joy em um artigo publicado na Wired Magazine, Berardi (2017) nos alerta para o risco de essa utopia da informação ilimitada converter-se na distopia da automação total que dispensa completamente a ação e a vontade humanas. Focando-se no desenvolvimento das nanotecnologias e no entrelaçamento cada vez maior entre tecnologias da informação, biotecnologias e processos de simulação, o artigo fala de uma tendência que aponta na direção do surgimento de uma mente global incorporada à tecnosfera lógica, linguistica e operacional. Nesse cenário de automatismo total, é como se o futuro não precisasse mais de nós, pois todas as decisões que levariam até ele - ou o processo no qual um futuro é selecionado entre outros - estão cada vez mais nas mãos (ou nos cérebros) de máquinas inteligentes. Aqui ocorre o que podemos chamar de um paradoxo da decisão: na medida que a circulação de informações se torna mais rápida e mais complexa, o tempo disponivel para a elaboração de informações relevantes torna-se mais curto. Quanto mais o espaço é saturado pelas informações disponiveis, menos tempo há para entendimento e escolha conscientes.

É por esse motivo que há uma interdependência cada vez maior entre os dados incorporados ao maquinário informacional e as decisões a serem tomadas, já que não nos resta mais tempo para hesitação. O excesso de informações ao qual somos expostos hoje definha aos poucos nosso pensamento, embota nossa percepção e prejudica nossa capacidade analítica, que consiste justamente em distinguir o essencial do não essencial, em deixar de lado todo material perceptivo que não é importante ao que está em questão (tarefa praticamente impossivel quando somos saturados pelo mar de informações). Nosso próprio pensamento vai sendo gradativamente substituido pelo cálculo. Em um contexto em que tudo é tornado enumerável, a fim de poder ser convertido na linguagem do desempenho e da eficiência, aquilo que não pode ser calculado, capturado em dígitos, cessa de ser (Han 2018).

Quando o acontecimento é, enfim, antecipado e neutralizado por todo tipo de cálculo e de previsão estatística, quando nossa potência de agir é dispensada em prol dos automatismos tecnolinguísticos, tanto a criação de novos possiveis quanto a sua efetuação, tornam-se comprometidas. Em um cenário no qual os próprios seres humanos tornam-se obsoletos, também a potência necessária para a efetuação dos possiveis desaparece. Se em alguma medida o desaparecimento dos humanos da face da Terra é algo desejado pelas ciberutopias transcendentalistas que almejam a digitalização total dos corpos (pois, nessa hipótese, é só o corpo que se torna obsoleto, posto que os humanos - ou seus cérebros - ainda agem efetivamente na esfera informacional), nesse outro cenário somos dispensados por completo, pois a própria atividade cognitiva é também submetida a cadeias lógicas e causais. A crise no âmbito dos possiveis se expressa, dessa maneira, em uma de suas piores versões.

Por outro lado, devemos reconhecer que há quem veja com bons olhos a possibilidade da automação total: na utopia aceleracionista, ela será, ao contrário, emancipatória. Será a automação propiciada pelas máquinas aquilo que irá nos libertar do trabalho alienado (o trabalho na sua forma capitalista), propiciando que estejamos livres, portanto, para nos dedicarmos à criação de nossas próprias vidas. Para Srnicek e Williams (2016), é o automatismo das máquinas o que irá nos devolver nossa autonomia no mundo, libertando nossa ação. Mas o que fariamos, de fato, com tanto tempo livre? É a pergunta que também faz Felix Guattari (1990) ao observar, ainda nos anos 1980 quando escreveu suas Três Ecologias, que o desenvolvimento do trabalho maquínico seria redobrado pela revolução infor- 
mática. Quando tentam responder essa questão, os autores aceleracionistas remetem-nos apenas a noções vagas de criação, liberdade e libertação do desejo. Nesse futuro pós-capitalista no qual os humanos não trabalham, há tempo para lazer, para aprender um instrumento musical, ler literatura, socializar com amigos, praticar esportes e, enfim, trabalhar apenas com o que se gosta. Parece-nos que esse tipo de imaginário futurista não dá a devida importância às atuais formas de controle que atuam no âmbito da esfera informacional, ou ao tamanho acoplamento do homem às máquinas que hoje não é só corporal (o trabalho da linha de montagem) mas também subjetivo. Não são hoje só nossos gestos que estão submetidos às máquinas, mas também nossos processos cognitivos e subjetivos estão acoplados intimamente aos mecanismos informacionais. Como nos lembra Berardi (2011, 2017), para chegarmos a tal utopia (a do mundo pós-trabalho), seria preciso antes de tudo um processo de libertação no campo das subjetividades coletivas que se veem hoje cada vez mais submetidas à lógica informacional.

Para o filósofo Byung-Chul Han (2018), o que os processos automáticos aos quais o mundo está submetido hoje provocam é, ao contrário, uma verdadeira crise da ação. A sociedade da informação total suprime as ações humanas, pois nela predominam apenas diferentes estados do mesmo. O autor compreende, a partir de Hannah Arendt, o agir como aquilo que põe um inicio em algo, que permite que algo novo comece (um novo mundo, por exemplo). Os automatismos de todo tipo levam hoje ao que Han $(2018,61)$ chama de uma atrofia das mãos: "os aparatos digitais fazem com as que mãos murchem", ainda que isso signifique para muitos uma espécie de alivio, já que remete, em um nivel mais profundo, àquela sensação de libertação do fardo da matéria... O ser humano do futuro não precisa mais de mãos, não precisa mais lidar (handle) com as coisas, especialmente as coisas materiais, pois agora só interessam informações intangiveis. "No lugar das mãos, entram os dedos. O novo ser humano passa os dedos, em vez de agir" (Han 2018, 62). É essa atrofia das mãos o que nos torna incapazes de ação. Em meio aos automatismos, a operação entra no lugar da ação, e nenhuma decisão em sentido enfático precede a ela. A hesitação ou a vacilação, que seriam, a princípio, constitutivas do agir, são percebidas como um distúrbio operativo, pois prejudicam a eficiência do sistema.

Recorrendo ao termo de Warren Neidich, Berardi (2017) usa a seguinte expressão para se referir ao conjunto de automatismos que, ao dispensarem a ação necessária para a criação do novo, realizam hoje essa captura do futuro: statisticon, um poderoso mecanismo que reduz os acontecimentos em termos de probabilidade e previsibilidade. Esse tipo de preempção estatística é o modo atual de funcionamento dos governos, do mercado, ou, em resumo, a forma contemporânea do poder político e econômico, que controla nossas condutas de forma determinística. É por isso que podemos dizer que o determinismo hoje não é mais só uma metodologia filosófica que descreve a evolução em termos de implicações causais, mas é também uma estratégia política de governo dos corpos e das subjetividades, que tem como objetivo introduzir cadeias causais no mundo, especialmente no meio social. A estratégia determinista visa subjugar o futuro, restringindo as tendências a um modelo prescrito.

Para exemplificar a maneira determinista como essas prescrições agem em nosso cotidiano, fazendo com que nossas ações se entrelacem intimamente aos automatismos dos sistemas de informação, Berardi (2017) descreve a seguinte situação: o funcionamento de diversas instituições depende hoje dos automatismos tecnolinguísticos, por exemplo, se um locatário não pagar seu aluguel em dia, será despejado de seu apartamento, se um estudante não pagar as mensalidades do seu curso, será desligado da universidade etc. Nesses casos, porém, a execução do despejo do locatário ou do desligamento do aluno não correspondem à ação de um agente humano, mas são consequências inscritas na máquina técnica. Essas consequências agem no mundo real como se fossem necessidades lógico-matemáticas, e mesmo que elas não sejam, as máquinas linguís- 
ticas registram os comportamentos e os traduzem como consequências: eventos reais são ativadores de funções matemáticas inscritas na máquina. No computador da empresa imobiliária há uma cadeia lógica indicando que o locatário que não pagar o aluguel será despejado. Essa implicação, entretanto, não é lógica ou natural, mas sim reforçada pela automação da vontade, pela transcrição automática de um determinado tipo de relação social em códigos informacionais (Berardi 2017).

Esse é apenas um exemplo de como nossas ações estão entrelaçadas - ou melhor, submetidas - a esse tipo de mecanismo, mas há também situações mais cotidianas, como os anúncios online personalizados, por trás dos quais existem complexos algoritmos que antecipam e criam nossos padrões de compra; a "arquitetura de escolhas" (Uncertain Commons 2013), técnica do marketing que organiza o meio para materializar o curso de ação de um futuro sobre os outros, fazendo da tomada de decisões um problema de engenharia social; os aplicativos móveis de trânsito e localização que registram nossos passos e traçam para nós o melhor caminho; os aplicativos que nos sugerem o que ver ou ouvir, moldando nossos gostos e mantendo-nos em nossa bolha informacional; os caixas eletrônicos e demais interfaces maquínicas que condicionam nossos gestos; ou toda forma de sistema tecnolinguístico com o qual interagimos e que registra qualquer tipo de informação sobre nós. Essa é uma forma, como já mencionamos, mais molecular de controle do futuro, pois age diretamente no comportamento e na subjetividade dos indivíduos, traçando seus próximos passos. Porém, não podemos esquecer que, pela característica cumulativa dos grandes bancos de informações, aí também age uma dimensão molar que se refere a táticas de governo das populações (Foucault 2008). É onde entram as estatísticas, os grandes dados, os mapas sociais dai derivados, que permitem às grandes instituições (o governo, o mercado, o capital) traçar o futuro de forma mais generalizante e homogênea.

Apesar de parecerem naturais, já que estamos acostumados a lidar com todo tipo de interface digital no cotidiano das grandes cidades, esses automatismos tecnolinguísticos são, na verdade, armadilhas deterministicas através das quais a vasta gama de possibilidades é reduzida ao fluxo estreito das probabilidades. Assim que o possivel é capturado por esses mecanismos de controle, ele é reduzido à categoria de provável, sendo este último, por sua vez, reforçado como necessário (Berardi 2017). Possível, provável, necessário... como diferenciar essas categorias de futuridade? $\mathrm{Na}$ forma como estamos compreendo-as aqui, os possiveis, em quantidade sempre muito maior do que os prováveis podem converter-se nesses últimos ao passarem pelo filtro das máquinas de captura, reduzindo, assim, sua multiplicidade característica. Os poucos prováveis que restam são, por sua vez, refinados por mecanismos ainda mais complexos que, a partir de cálculos extremamente precisos, chegam, enfim, a um futuro necessário, que é então instalado em nosso horizonte de expectativas.

A transformação do possivel em provável não é, porém, algo novo, que tenha surgido apenas no estágio atual de evolução das máquinas de controle, mas um resultado do modo de pensar a realidade instalado pelas ciências modernas. Nietzsche (2012) nos lembra que a função da ciência é prometer. Mesmo que a promessa seja também uma categoria pertencente ao futuro, nesse momento seria mais interessante pensar que a ciência surge, acima de tudo, para prever, reconhecendo, é claro, que a promessa e a previsão, mesmo não sendo a mesma coisa, estão muito próximas, pois ambas se referem a maneiras de comprometer o futuro, de firmá-lo ou de trazê-lo ao presente. Tarde (2007) nos lembra que se o possivel tinha como origem o sentimento habitual da dúvida ("é possivel que seja isso..."), à medida que a razão progride e a ciência se fortalece, a ideia de possibilidade encontra na noção de lei uma confirmação, devendo, a partir de então, mostrar-se fundada na natureza das coisas. Ainda para o autor, a ciência deve ser considerada como afirmação de necessidades, de relações certas que unem termos reais ou não, pois o que ela faz constantemente é afirmar que, 
dada tal condição, tal efeito se seguirá. Podemos dizer, enfim, com Tarde (2007), que os possiveis são o objeto próprio da ciência, pois é a eles que ela se volta, é com eles que ela lida para, a partir daí, reduzi-los a probabilidades ou necessidades.

\section{Especulação firmativa e afirmativa}

Se são as ciências, portanto, de forma ampla, que realizam pela primeira vez de maneira sistemática a captura do possivel e sua transformação em provável ou necessário, devemos reconhecer que não há uma prática moderna que tenha feito isso de forma tão eficaz (muito antes das ciências informáticas) como as ciências econômicas. A economia financeira foi a primeira ciência estritamente orientada para um futuro incerto, entendido ao mesmo tempo como oportunidade e como ameaça. O coletivo anônimo Uncertain Commons (2013), formado por pensadores de diferentes áreas, analisa que a chave para entendermos esse processo de captura do possivel pelas ciências está em uma virada que acontece no significado de um termo muito importante na abordagem dessas categorias, virada essa que teria acontecido em função justamente do surgimento das ciências econômicas: trata-se de uma mudança na concepção do termo especulação.

A especulação hoje está na moda. Vivemos em um mundo moldado por práticas de especulação, desde ciências probabilísticas (análises de risco, análise do genoma humano) e técnicas antecipatórias (compra e venda de ações no mercado financeiro, previsões sobre o desenvolvimento tecnológico), até instituições governamentais voltadas ao futuro (Painel sobre mudanças climáticas, Organização mundial da saúde). Todas essas são práticas que têm em comum uma tentativa de importar o futuro para o presente, precisando, para isso, objetivá-lo de alguma maneira. Mas o que significa, enfim, especular sobre algo, ou, mais especificamente, sobre o futuro? O termo especulação tem em sua origem filosófica (spàs, do grego e do sânscrito, ou speculatio, do latim) o sentido de contemplação, observação, exame, exploração... trata-se de observar e compreender algo que não está claramente evidente, ou de perceber melhor, e, mais importante, sentir, ser afetado. Essa ambiguidade entre algo que se apresenta claramente à nossa percepção, mas que ao mesmo tempo precisa ser apreendido, pois mantém ainda um aspecto de obscuridade, é o que faz da especulação algo que se volta ao campo do desconhecido (Uncertain Commons 2013).

A partir da modernidade e do nascimento do capitalismo no século 17, o termo species (aparência ou forma) começa a ser relacionado ao dinheiro ou à moeda. A palavra especulação, a partir daí, oscila entre pensamento e dinheiro, entre intelecto e capital, tendo, portanto, dois registros semântico-conceituais distintos: um cognitivo e outro econômico. Especular passa a significar tanto contemplar, ponderar, fazer estimativas, criar hipóteses, quanto comprar e vender para poder lucrar com o futuro crescimento e queda do valor de mercado, ou seja, investir na esperança do lucro, porém sabendo do risco da perda. Tanto no âmbito do pensamento, quanto no do capital, a especulação constitui uma tentativa de trazer o futuro para o presente. Ambos os registros tentam representar e calcular um futuro que, a princípio, é imprevisivel, irrepresentável, incalculável por definição. Essa forma moderna de especulação é o que os autores do coletivo Uncertain Commons (2013) chamam de especulação firmativa (firmative speculation), ou seja, um modo especulativo que procura fixar, delimitar, restringir, fechar, tornar as coisas definitivas ou "firmadas", sendo que o termo "firmar", aqui, aproxima-se do significado literal de tornar firme, ou de "solidificar" as possibilidades do futuro.

Se a especulação em sua forma econômica tem como característica "firmar" as possibilidades, é preciso lembrar que existem ainda outros modos de reconhecer e apreender as energias latentes do cotidiano. Se o tipo de especulação que acabamos de ver - aquele que tem sua origem no pensamento moderno - é descrito como firmativo, esses outros modos possiveis de especular seriam, por sua vez, afirmativos. Especular de forma afirmativa corresponde a um tipo de produção de futuros que recusa o fechamento das potencialidades, mantendo-se aberto à multiplicidade 
de futuros cujo contexto de atualização nunca pode ser completamente antecipado. Se a especulação firmativa mina o campo dos possiveis, a especulação afirmativa o expande. Esse modo de especulação inclui o jogo, a intuição, a criação, engajando-se ativamente com aquilo que a noção de risco evita: a incerteza. Abraçando a incerteza, é possivel mantermo-nos receptivos à diferença, às mudanças, às contingências, desestabilizando os caminhos já garantidos pela antecipação gerenciada e abrindo-nos a estados desconhecidos cujo contexto de atualização ainda não está aqui (Uncertain Commons 2013).

Os autores do coletivo Uncertain Commons (2013) deixam claro em seu Manifesto essa diferenciação entre os dois tipos de especulação, incentivando práticas que, afirmando a multiplicidade das possibilidades, e não a sua redução, rompam com o modelo da previsão de futuros. Porém, quando os mesmos autores tentam exemplificar quais seriam hoje essas práticas de especulação afirmativa, acabam por generalizar demasiadamente o método em questão, já que a lista de exemplos é extensa e parece referir-se praticamente a qualquer ato de resistência aos mecanismos de poder vigentes. Para os autores, a especulação afirmativa permeia hoje instalações de arte interativa, jogos de videogame, inovações na arquitetura urbana, realidades virtuais, grafite, manifestos, Parkour, pirataria, dentre outros tipos de práticas subversivas. Esse tipo de especulação pode atuar também na própria ciência, quando essa se aproxima da experimentação artística, criando hibridismos entre os dois domínios.

Esse método que afirma e intensifica possiveis estaria também na prática dos historiadores que veem no passado um locus de potencialidade, criando, a partir daí, histórias alternativas, novas constelações de eventos que escapam à narrativa tradicional e hegemônica. Estaria, ainda, nas especulações sobre um possivel mundo sem os humanos (já que a maioria dos futuros são feitos para nós), dentre outros futuros alternativos imaginados pela literatura ou pelo cinema. E, por último, mas não menos importante, estaria nas práticas de criação colaborativa que se dão no ciberespaço, como na multiplicação dos memes, na criação de softwares livres, nos manifestos dos hackers etc. (Uncertain Commons 2013). Aqui, a mesma rede informacional que, em função dos automatismos que a permeiam, é vista como aquilo que nos imobiliza, bloqueando nossa potência de agir, também é ao mesmo tempo aquilo que permite um tipo de conexão inédita entre as inteligências, o que favoreceria, a partir dessa nova composição, uma liberação de seu potencial de criação coletiva.

Por fim, a tentativa de libertar o futuro das restrições que têm lhe sido impostas pelas máquinas de previsão e controle - sejam os algoritmos que constituem o big data, sejam as previsões que apontam para um futuro hipertecnológico, futuro esse que predomina no imaginário ocidental não consiste apenas em uma nova composição entre humanos e máquinas, como acabamos de mencionar, um novo agenciamento coletivo que libere a potência da criatividade humana, mas também em resgatar outras formas de imaginação coletiva. Como afirma Suely Rolnik (2018), para conseguirmos nos reapropriar da força de criação e de cooperação da qual temos sido destituídos pelas atuais formas de controle do capitalismo cognitivo, seria preciso primeiramente uma desidentificação com os modos de vida que tal regime construiu. Para a autora, precisamos, acima de tudo, agir micropoliticamente, afirmando devires cujos efeitos coloquem em risco a continuidade das formas vigentes. Trata-se, enfim, de também atentar para formas minoritárias de imaginar o futuro, ancoradas em outras temporalidades que não a moderna, em uma tentativa de descolonizar nossas formas de imaginar e de produzir mundos, fazendo com que ajam no sentido de combater a condição que o realismo capitalista os tem colocado.

Afirmando o método especulativo como aquilo que expande o campo dos possíveis, podemos concluir, enfim, que não existe um determinado futuro nos esperando em um horizonte longínquo - o futuro hipertecnológico, seja ele utópico ou distópico -, mas muitos futuros (ou mundos) disputando o presente pela sua realização. Tudo 
o que precisamos fazer é prestar atenção a esses possiveis, para assim podermos dar à luz outras versões do futuro, não aquelas já prováveis ou previstas pelas técnicas de antecipação, mas futuros ainda impensados, outros mundos que estão, nesse exato momento, também reivindicando por um chamado à existência. Ouvir esses chamados constitui-se como dever ético e político de nossos tempos, não só para que se possa imaginar outros futuros, mas também para que se possa criá-los.

\section{Referências}

Benjamin, Walter. 2012. Sobre o conceito de história. In Magia e técnica, arte e politica, Obras escolhidas, vol. 1, 241-252. São Paulo: Brasiliense.

Berardi, Franco. 2011. After the future. Oakland: AK Press.

Berardi, Franco. 2017. Futurability: the age of impotence and the horizon of possibility. New York: Verso.

Danowski, Déborah e Eduardo Viveiros de Castro. 2014. Há mundo por vir? Ensaio sobre os medos e os fins. Florianópolis: Cultura e Barbárie.

Debaise, Didier e Isabelle Stengers. 2017. The insistence of possibles: towards a speculative pragmatism. Parse Journal 7: 13-19. https://doi.org/10.3917/mult.065.0082

Deleuze, Gilles e Felix Guattari, 2012. Mil platôs. capitalismo e esquizofrenia 2, vol. 3. Rio de Janeiro: Ed. 34.

Deleuze, Gilles e Felix Guattari. 2010. O que é a filosofia? São Paulo: Ed. 34.

Deleuze, Gilles. 1992. Post-scriptum sobre as sociedades de controle. In Conversações, 223-230. São Paulo: Ed. 34

Deleuze, Gilles. 2010. Sobre o teatro: um manifesto de menos. O esgotado. Rio de Janeiro: Zahaar.

Eshun, Kodwo. 2003. Further considerations on Afrofuturism. The new centennial review 3 (2): 287-302. https:// doi.org/10.1353/ncr.2003.0021

Fisher, Mark. 2009. Capitalist realism: is there no alternative? Winchester: O Books, 2009.

Foucault, Michel. 2008. Segurança, território, população. Curso dado no Collège de France. São Paulo: Martins Fontes.

Grosz, Elizabeth. 2004. The nick of time: politics, evolution and the untimely. Crows Nest: Allen \& Unwin.

Guattari, Felix. 1990. As três ecologias. Campinas: Papirus. Han, Byung-Chul. 2018. No enxame: perpectivas do digital. Petrópolis: Vozes.
Kaiser, Mario. 2015. Reactions to the future: the chronopolitics of prevention and preemption. NanoEthics 9 (2): 165-177. https://doi.org/10.1007/s11569-015-0231-4.

Lapoujade, David. 2016. Por uma utopia não utópica? In O novo espírito utópico, organizado por Adauto Novaes, 115-128. São Paulo: Edições Sesc.

Lapoujade, David. 2017. As existências mínimas. São Paulo: $\mathrm{n}$-1 edições.

Lazzarato, Maurizio. 2006. As revoluções do capitalismo. Rio de Janeiro: Civilização Brasileira.

Massumi, Brian. 2010. The future birth of the affective fact: the political ontology of threat. In The affect theory reader, organizado por Melissa Gregg e Gregory J. Seigworth, 52-70. London: Duke University Press.

Nietzsche, Friedrich. 2012. A gaia ciência. São Paulo Companhia das Letras, 2012

Pelbart, Peter Pál. 1993. A nau do tempo-rei: sete ensaios sobre o tempo da loucura. Rio de Janeiro: Imago.

Rolnik, Suely. 2018. Esferas da insurreição: notas para uma vida não cafetinada. São Paulo: n-1 edições.

Shaviro, Steven. 2018. Unpredicting the future. Alienocene: Journal of the First

Outernational. Acessado em 11 maio. 2018, https://alienocene.com/2018/04/01/futurity-andsciencefiction

Srnicek, Nick e Alex Williams. 2016. Inventing the future: postcapitalism and a world without work. New York: Verso.

Tarde, Gabriel. 2007. Os possiveis. In Monadologia e sociologia - e os outros ensaios, 191-233. São Paulo: Cosac Naify.

Uncertain Commons. 2013. Speculate this! Durham: Duke University Press

\section{Alana Soares Albuquerque}

Doutora e mestre em Psicologia Social e Institucional pela Universidade Federal do Rio Grande do Sul (UFRGS), em Porto Alegre, RS, Brasil. Psicóloga graduada pela Universidade Federal do Rio Grande (FURG), em Rio Grande, RS, Brasil. Pesquisadora do grupo Corpo, Arte e Clinica, da UFRGS.

Os textos deste artigo foram revisados pela Poá Comunicação e submetidos para validação da autora antes da publicação. 